This item is the archived peer-reviewed author-version of:

Changing publication patterns in the social sciences and humanities, 2000-2009

\title{
Reference:
}

Engels Tim, Ossenblok Truyken, Spruyt Eric.- Changing publication patterns in the social sciences and humanities, 2000-2009

Scientometrics: an international journal for all quantitative aspects of the science of science and science policy- ISSN 0138-9130 - 93:2(2012), p. 373-390

Full text (Publisher's DOI): https://doi.org/10.1007/S11192-012-0680-2

To cite this reference: https://hdl.handle.net/10067/950350151162165141 


\section{Changing publication patterns in the social sciences and humanities, 2000-2009}

Tim C. E. Engels

Centre for R\&D Monitoring (ECOOM), University of Antwerp, Middelheimlaan 1, 2020 Antwerpen, BELGIUM, and

Antwerp Maritime Academy, Noordkasteel-Oost 6, 2030 Antwerpen, BELGIUM

Truyken L. B. Ossenblok

Centre for R\&D Monitoring (ECOOM), University of Antwerp, Middelheimlaan 1, 2020 Antwerpen, BELGIUM

Eric H. J. Spruyt

Department of Research Affaires, University of Antwerp, Middelheimlaan 1, 2020 Antwerpen, BELGIUM

Corresponding author: Tim Engels

$\mathrm{T}+3232653034$

F+ 3232653011

tim.engels@ua.ac.be 


\begin{abstract}
An analysis of the changing publication patterns in the social sciences and humanities (SSH) in the period 2000-2009 is presented on the basis of the VABB-SHW, a full coverage database of peer reviewed publication output in SSH developed for the region of Flanders, Belgium. Data collection took place as part of the Flemish performance-based funding system for university research. The development of the database is described and an overview of its contents presented. In terms of coverage of publications by the Web of Science we observe considerable differences across disciplines in the social sciences and humanities. The overall growth rate in number of publications is over $62.1 \%$, but varies across disciplines between $7.5 \%$ and $172.9 \%$. Publication output grew faster in the social sciences than in the humanities. A steady increase in the number and the proportion of publications in English is observed, going hand in hand with a decline in publishing in Dutch and other languages. However, no overall shift away from book publishing is observed. In the humanities, the share of book publications even seems to be increasing. The study shows that additional full coverage regional databases are needed to be able to characterise publication output in the social sciences and humanities.
\end{abstract}

Keywords: social sciences; humanities; language use; publication types; books; Flanders

MSC: 01; 94

JEL: A14; O38 


\section{Introduction}

Several countries have gradually evolved towards performance-based funding of university research (Hicks, 2012). This is also the case for Flanders, the northern Dutch-speaking region of Belgium, where part of the government funding for research is distributed over the universities according to their share of articles indexed in Thomson Reuters' Web of Science (WoS) since 2003. Using the WoS, research in the natural, life and technical sciences has been meticulously monitored over the last 25 years (Debackere \& Glänzel, 2004; Luwel, 2000; Moed, Luwel, Houben, Spruyt, \& Van Den Berghe, 1998). An early attempt to extend monitoring to items that are not included in the WoS proved feasible (Moed, Luwel, \& Nederhof, 2002). Hence, because thus far the coverage of social sciences and humanities ( $\mathrm{SSH}$ ) publications in the WoS remains limited (Adams \& Testa, 2011; Archambault, Vignola-Gagne, Cote, Lariviere, \& Gingras, 2006), the logic approach for the Flemish government was to instruct an independent body to map the SSH publications that are not indexed in the WoS as well. In 2008 the government provided the legal framework for the construction of the Flemish Academic Bibliographic Database for the Social Sciences and Humanities ("Vlaams Academisch Bibliografisch Bestand voor de Sociale en Humane Wetenschappen" or "VABB-SHW") in the Flemish university financing decree and the modified BOF regulation on the financing of the University Research Fund ("Bijzonder Onderzoeksfonds" or "BOF"). The VABB-SHW has provided the Flemish government with a useful tool to further fine-tune the distribution of research funding over universities in Flanders, and allows to analyse changing publication patterns in the peer reviewed literature over a ten year period. The present article describes how the database was constructed and elaborates on the specific properties of peer reviewed publications written by SSH scholars affiliated with Flemish universities.

In ordering the VABB-SHW, the Flemish government met the demands voiced by researchers, trade unions and universities to take into account the specific characteristics of the SSH when allocating research funds among the universities, in particular the fact that publications by SSH researchers working in Flanders often appear in books and/or in Dutch. This observation is similar to that made elsewhere: the scholarly output of social scientists and humanities scholars is diverse in terms of publication types and languages (Hicks, 2004; Hornbostel, 2008). As a result national or regional databases are needed to obtain full coverage of publications in the social sciences and humanities (Martin et al., 2010). Probably the best known database of this kind, albeit covering all research fields, is the Norwegian CRISTIN database (Schneider, 2009; Sivertsen, 2010). Contrary to that database, however, the VABB-SHW was built up retrospectively in order to obtain a ten year window and hence a stable new parameter for the BOF-key (Debackere \& Glänzel, 2008). Although the weight of this parameter in the 2011 BOF-key is restricted to $2.6 \%$, the new database will probably have a wider impact both in terms of funding and usage. This is because the parameter will also be reused for the distribution of the university operating budgets and other research funds (Engels, Spruyt, Glänzel, \& Debackere, 2009), and because the universities 
themselves will probably also use the database for internal purposes at various levels as is the case in Norway (Sivertsen, 2010).

\section{Construction of the VABB-SHW}

The VABB-SHW gathers the bibliographic references of published research outputs by scholars who are affiliated with Flemish universities ${ }^{1}$ and are active in the SSH. In accordance with the rules stipulated in the BOF regulation, the following five publication types are eligible for inclusion in the VABB-SHW:
a) articles in journals;
b) books as author;
c) books as editor;
d) articles or chapters in books;
e) proceedings papers that are not part of special issues of journals or edited books.

The BOF regulation further lists a number of basic criteria which eligible outputs need to meet. They are to:

a) be publicly accessible;

b) be unambiguously identifiable by ISBN or ISSN number;

c) make a contribution to the development of new insights or to applications resulting from these insights;

d) have been subjected - prior to publication - to a demonstrable peer review process by scholars who are experts in the (sub)field to which the publication belongs. Peer review should be done by an editorial board, a permanent reading committee, external referees or else by a combination of these.

The Flemish government decided to entrust the interuniversity Centre for $R \& D$ Monitoring ("Expertisecentrum Onderzoek en Ontwikkelingsmonitoring" or "ECOOM") with the construction of the VABB-SHW and the executive committee of ECOOM, in turn, instructed the team of the University of Antwerp to implement the actual construction of the database. The Antwerp ECOOM team was given the responsibility for the technical development of the database and as such coordinated the different stages of the database construction in close collaboration with colleagues of other universities, in particular the Leuven ECOOM team.

\footnotetext{
${ }^{1}$ Publications by researchers employed at university colleges are also accepted for inclusion in the VABB-SHW database. However, not all university colleges submitted data regarding publications carrying an address of their institution because these publications, while included in the publicly accessible online version of the VABB-SHW, are not taken into account for the calculation of the BOF-key. Hence, given the incomplete character of the data supplied by the university colleges, we limit our analysis to the publications written by scholars affiliated with one or more Flemish universities.
} 
The Flemish government simultaneously decided to establish an Authoritative Panel (“Gezaghebbend Panel" or "GP”), which is composed of 18 professors affiliated with Flemish universities and university colleges and whose expertise covers the main SSH disciplines. The GP works independently of the Flemish government and is supported technically by ECOOM and administratively by the Flemish Interuniversity Council ("Vlaamse Interuniversitaire Raad" or "VLIR"). The task of the GP is to evaluate which of the journals and book publishers with whom researchers affiliated with a Flemish university published at least once in the period 2000-2009 fulfil the aforementioned criteria. The universities also installed a GP steering committee ("Bureau GP"), consisting of 5 GP members, one from each university, in order to outline the working method and prepare the meetings of the plenary panel. Most GP members also chair a disciplinary subpanel which they consult in the processes of journal and publisher selection. In addition to the criteria of the BOF regulation, the GP decided to include only publications of at least four pages in the VABB-SHW.

At the end of 2008, the executive committee of ECOOM adopted the Metadata Object Description Schema (MODS) architecture of the database ${ }^{2}$. This approval gave the green light to the universities to start with the preparations for the first data submissions to be forwarded to the Antwerp ECOOM team by 1 September 2009. Each institution addressed issues regarding the completeness in terms of number of records in their bibliographic databases, regarding the correctness and completeness of the data and metadata for each record, and regarding the compliance with the MODS architecture. The university libraries invoked the help of all faculty and researchers in SSH to check whether all their publications since 2000 were entered correctly and completely in the local bibliographic database. This included the addition of ISSN and ISBN that were often not systematically available in the databases. Several librarians per university worked intensively in order to clean and upgrade the data until a first test of compliance with the MODS architecture was possible. To this end, the Antwerp ECOOM team provided a parser to check the XML structure of the data, to check conformity with the MODS architecture and to check the validity of each record in terms of minimally required fields and data correctness. Using a detailed list of errors, librarians could then apply further corrections. The universities also agreed on the mapping of local publication types to the VABB-SHW publication types.

In the fall of 2009 the Antwerp ECOOM team then further upgraded, cleaned and standardised the data. In a first phase this included the addition and correction of ISSN and ISBN using record listings, the standardisation of ISSN and ISBN (into ISBN-13), the standardisation of journal names using the ISSN.org database, and the standardisation of book publisher names using isbndb.com and other catalogue lists. Subsequently erroneously submitted records such as abstracts, book reviews and editorials were searched for and deleted from the database after consultation with the universities. The Antwerp ECOOM team also listed all potentially WoS

\footnotetext{
${ }^{2}$ More information regarding MODS can be found at http://www.loc.gov/standards/mods/, while the VABB-MODS as well as the parser is available at http://anet.ua.ac.be/desktop/vabb/.
} 
indexed records and looked up and added their ISI UT-codes if missing but available. Lastly, possible duplicates in the database were identified using a set of keys and algorithms that compared the records' UT-codes, digital object identifiers, ISSN/ISBN, year of publication, page numbers (if applicable), and text strings made up of the least occurring characters in the record titles. All potential duplicate records where presented as couples in the database and were, when indeed referring to the same publication, merged by a research assistant. Building on the deposited 2000-2008 publication descriptions, ECOOM handed over the first lists of journals, book publishers, book titles and proceedings papers to the GP by the end of 2009. Following the second data submission by the universities on 1 April 2010, the same data cleaning and standardisation procedures were applied before the lists were complemented with the sources of the additionally supplied records (outputs up to 2009).

In the VABB-SHW all records were assigned to disciplines on the basis of the author(s) affiliation(s) with a SSH unit, i.e. the research group, the research centre, the institute or the department in which the author carries out research. In other words, all SSH research units of the Flemish universities were assigned to a discipline. After the validation of this classification of units into disciplines by the universities and the GP, the classification was used to assign authors and their publications to disciplines. As a result all publications were assigned to one or more of the following disciplines (1) in the Humanities: Archaeology; Art history (including Architecture and Arts); Communication studies; History; Law; Linguistics; Literature; Philosophy (including History of ideas); Theology (including Religious studies), and/or (2) in the Social sciences: Criminology; Economics \& Business (including Library \& Information science); Educational sciences; Political science; Psychology; Sociology (including Social health sciences). Publications that could not (unambiguously) be classified into one or more of the aforementioned 15 disciplines (for instance, publications of anthropologists) or that were published by university policy makers not affiliated with a SSH unit (for instance, publications on research policy) were assigned to one of three general categories, i.e. Social sciences-general, Humanities-general or Other.

This uniform and complete attribution of publications to disciplines, as well as the aforementioned data cleaning and standardisation processes, allowed the Antwerp ECOOM team to provide the GP with overviews of journals, book publishers, book titles and proceedings papers for the whole database and per discipline, thus facilitating the work of the GP and its disciplinary subpanels. The lists submitted to the GP also stated which journals and proceedings papers were partially or completely indexed in the WoS. The GP decided that these journals and proceedings papers fulfilled the criteria of the BOF regulation because articles indexed in the WoS are automatically included in the calculation of the BOF-key when carrying an address of a Flemish university. This GP decision, however, did have important consequences in that all articles published in journals that were added to the WoS during the period 2000-2009 were included for the calculation of the BOF-key, either as a WoS publication if indeed indexed in that database or as a GP-approved publication if not indexed in the WoS. 
On 1 October 2010, after almost a year of intensive work, the GP supplied ECOOM with the list of journals and book publishers that, according to the GP, apply a peer review procedure and publish scholarly content (Ghesquière, Van Bendegem, Gillis, Willems, \& Cornelissen, 2011). The journal list included, in addition to the journals that were (partially) indexed in the WoS, all journals in which researchers affiliated with a Flemish university had published and that mentioned their peer review policy on their website or, in case no website was available, in their colophon. The selection of book publishers proved more difficult because only few publishers submit all their books to peer review. Therefore, after elaborate discussion and consideration of alternatives, the GP decided to include only the book publishers that had been selected in Norway for the level 2, i.e. the most prestigious and selective international book publishers (Sivertsen, 2010). In accordance with the BOF regulation only the articles that appeared in these selected journals and the books, edited books and book chapters that appeared with these selected publishers, have been included in the VABB-SHW, provided that they also met the extra criterion of a minimum length of four pages. With regard to proceedings papers, the GP decided to include all papers of four pages or more that appeared in a serial proceedings volume, i.e. carrying an ISSN, or that were published with one of the selected book publishers. On the basis of the GP's decisions the Antwerp ECOOM team subsequently narrowed down the set of unique records $(\mathrm{N}=86558)$ to those that met the BOF and GP criteria, i.e. 29921 records or $34.6 \%$ of the total. On 15 October 2010 the Antwerp ECOOM team forwarded the result of this exercise to the universities so that the lists of publications that qualified for inclusion in the first version of the VABB-SHW could be validated and, whenever necessary, be amended by submitting proof of ISSN, ISBN or page numbers no later than 15 November 2010. This strict approach enabled ECOOM to forward the results of the first version of the VABB-SHW to the Flemish government on 1 December 2010 and publish the lists of journals and book publishers together with the public version of the database on the ECOOM website (www.ecoom.be/vabb).

\section{Characterisation of publications in the social sciences and humanities}

The first version of the VABB-SHW encompassed 29921 publications, i.e., outputs stemming from the period 2000-2009 with the author or at least one of the co-authors affiliated with a Flemish university.

Figure 1 provides an overview of the nature of the publications included in the VABB-SHW. Two main output groups can be discerned in this respect: the first group consists of 18946 publications $(63.3 \%)$ that were not indexed in the WoS but met the BOF criteria, the GP-approved selection of journals and book publishers as well as the GP-imposed minimum required content of four pages. The second group counts 10975 publications (36.7\%) that are described in the WoS and qualified for inclusion in the calculation of the BOF-key. These two groups will henceforth be referred to as VABB-GP and VABB-WoS, respectively, and their union as VABB-SHW. 


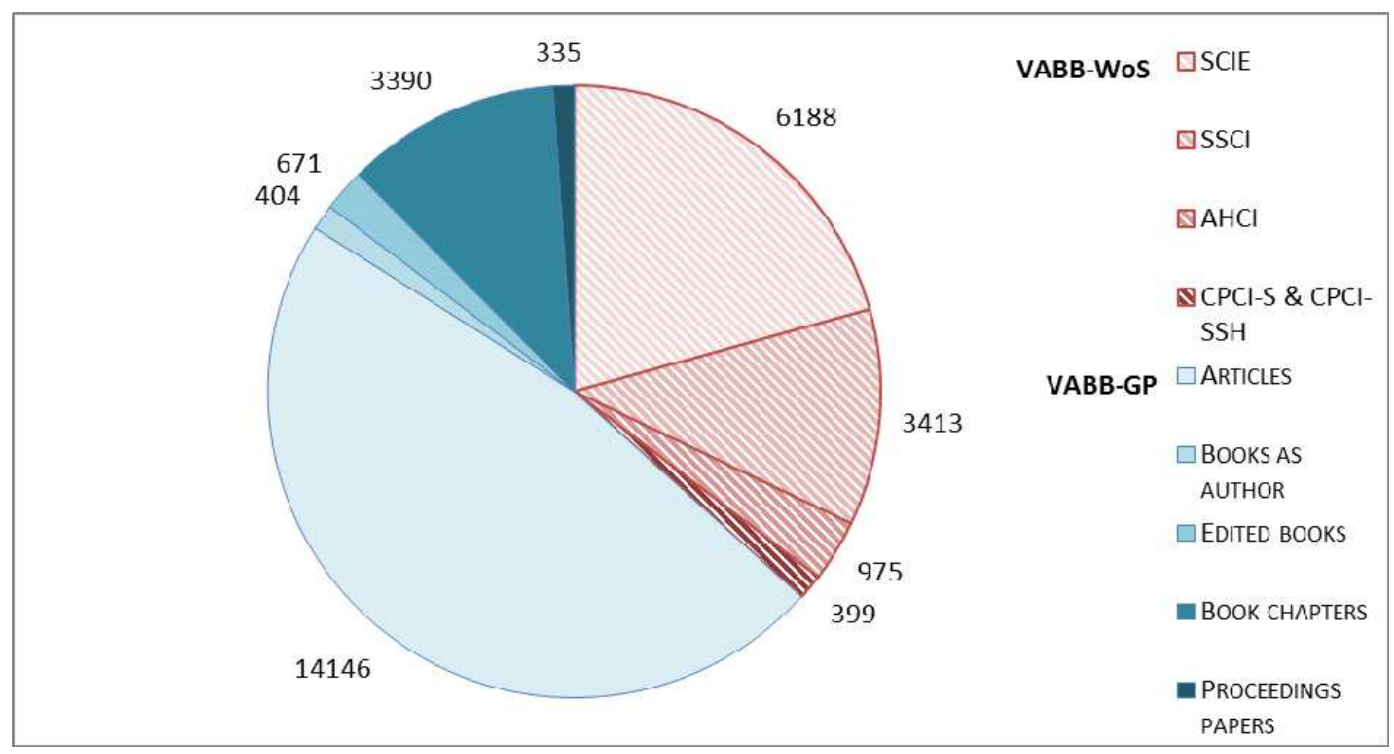

Figure 1: Number of publications per type included in the first version of the VABB-SHW (VABB-GP and VABB-WoS).

The 18946 VABB-GP publications can be further subdivided according to publication type: 14146 journal articles, 404 books as author, 671 edited books, 3390 book chapters and 335 proceedings papers (see also Table 1). The 10975 VABB-WoS publications can also be further specified according to the WoS sub-database(s) in which they were captured: 6188 of the VABB-WoS publications were described in the Science Citation Index Expanded (SCIE), the largest subdatabase covering publications in the natural, life and technical sciences. More than half (3313) of these publications not only appeared in the SCIE, but were also captured in the Social Science Citation Index (SSCI) and/or the Arts and Humanities Citation Index (AHCI). That 2875 articles appear in the SCIE only may come as a surprise for a SSH database. This is mainly due to collaboration with the health sciences, e.g. by psychologists and sociologists, and to social scientists active in math intensive specialisms such as statistics and operations research that are prominent in faculties of economics and business. A second subtype consists of 3413 publications that were indexed in the SSCI (with 479 publications co-indexed in the AHCI) and a third subtype comprises 975 publications that were only entered in the AHCI. Finally, 399 proceedings papers were included in either of the two proceedings databases, namely the Conference Proceedings Citations Index - Sciences (CPCI-S) and the Conference Proceedings Citations Index - Social Sciences \& Humanities (CPCI-SSH).

Figure 1 shows that the combined publication types books as author, edited books and book chapters, merely account for $14.9 \%$ of the publications comprised in the VABB-SHW. However, these book outputs are more decisive in the composition of the BOF-key because books as author and edited books are assigned a weight factor of 4.0 and 2.0, respectively, while journal articles, 
book chapters and proceedings papers receive 1.0, 1.0 and 0.5 , respectively ${ }^{3}$. The GP is allowed by the BOF regulation to put forward proposals to change these weight factors. Moreover the GP can differentiate the weighting within publication types, as is the case in Norway where all eligible journals and book publishers are categorized into two levels (Sivertsen, 2010). However, such a differentiation could not be realised for the first version of the VABB-SHW because of the tight schedule and strict criteria stipulated in the BOF regulation (Ghesquière et al., 2011). Although differentiation in weighting could benefit book publications, it is especially the number of them that could increase in future versions of the VABB-SHW. It remains to be seen whether the resulting percentage of book publications will then more faithfully reflect percentages reported in the literature (Adams \& Testa, 2011; Nederhof, 2006; Sivertsen, 2009).

\section{Characteristics of the distinct disciplines}

Table 1 provides an overview of the number of publications by discipline and publication type in the first version of the VABB-SHW. Apart from listing the number of publications within each discipline, the Table also gives the distribution of the publication types within each discipline. The total number of unique records (by publication type) comprises the publications assigned to one or more of the $15 \mathrm{VABB}-\mathrm{SHW}$ disciplines as well as those categorized into one of the three general categories (Humanities-general, Social sciences-general, and Other). Hence the sum of the subtotal Humanities (that includes Humanities-general) and the subtotal Social sciences (that includes Social sciences-general) is larger than the total number of unique records.

Table 1 shows that the vast majority of the scholarly outputs in the database are journal articles $(82.6 \%)$, followed at considerable distance by book publications $(14.9 \%)$, while the number of proceedings papers currently contained in the database is very limited (2.4\%). The share of books and book chapters is higher in the Humanities $(n=3482$, i.e. $23.2 \%)$ than in the Social sciences $(n=1073$, i.e.7.2\%). Articles indexed in the WoS dominate in the Social sciences $(n=7656$, i.e. $51.6 \%)$ whereas they represent only about one in seven articles in the Humanities $(n=2165$, i.e. 14.4\%). The disciplines Law and Economics \& Business together account for almost a third of all publications in the database ( $15.6 \%$ and $14.9 \%$, respectively). The second largest disciplines are Sociology and Psychology representing $10.3 \%$ and $9.5 \%$ of the records in the database respectively. The disciplines with the lowest number of publications are Archaeology (1.3\%), Art history $(2.3 \%)$, Communication studies $(2.4 \%)$, and Criminology $(2.9 \%)$.

${ }^{3}$ In this study all journal articles receive a weight of 1.0. For the exact calculation of the BOF-key, however, journal articles that are indexed in the SCIE and/or the SSCI in a journal that has an impact factor are weighted according to the JCR Impact Factor in order to take into account the status of the journal (Debackere \& Glanzel, 2008). 
Table 1: Number of publications included in the VABB-SHW (VABB-GP and VABB-WoS) by discipline and by publication type.

\begin{tabular}{|c|c|c|c|c|c|c|c|c|c|}
\hline \multirow[t]{2}{*}{ Discipline } & \multicolumn{2}{|c|}{ Journal articles } & \multirow{2}{*}{$\begin{array}{c}\text { Book } \\
\text { Chapters } \\
\text { VABB- } \\
\text { GP }\end{array}$} & \multirow{2}{*}{$\begin{array}{c}\text { Books } \\
\text { as } \\
\text { editor } \\
\text { VABB } \\
\text {-GP }\end{array}$} & \multirow{2}{*}{$\begin{array}{c}\text { Books } \\
\text { as } \\
\text { author } \\
\text { VABB } \\
\text {-GP }\end{array}$} & \multicolumn{2}{|c|}{$\begin{array}{c}\text { Proceedings } \\
\text { papers }\end{array}$} & \multirow{2}{*}{$\begin{array}{c}\text { Total } \\
\\
\text { VABB } \\
\text {-SHW }\end{array}$} & \multirow{2}{*}{$\begin{array}{c}\% \text { in } \\
V A B B \\
-S H W\end{array}$} \\
\hline & $\begin{array}{c}\text { VABB } \\
\text {-GP }\end{array}$ & $\begin{array}{l}\text { VABB } \\
- \text { WoS }\end{array}$ & & & & $\begin{array}{l}\text { VABB } \\
- \text { WoS }\end{array}$ & $\begin{array}{l}\text { VABB } \\
\text {-GP }\end{array}$ & & \\
\hline Archaeology & 176 & 133 & 40 & 6 & 11 & 12 & 18 & 396 & 1.3 \\
\hline Art history & 295 & 150 & 135 & 38 & 12 & 22 & 28 & 680 & 2.3 \\
\hline Communication studies & 425 & 170 & 94 & 16 & 3 & 19 & 1 & 728 & 2.4 \\
\hline History & 773 & 193 & 233 & 52 & 28 & 0 & 19 & 1298 & 4.3 \\
\hline Law & 4018 & 144 & 320 & 89 & 55 & 11 & 20 & 4657 & 15.6 \\
\hline Linguistics & 908 & 457 & 511 & 135 & 59 & 54 & 83 & 2207 & 7.4 \\
\hline Literature & 631 & 143 & 376 & 87 & 36 & 0 & 31 & 1304 & 4.4 \\
\hline Philosophy & 786 & 603 & 279 & 42 & 30 & 36 & 9 & 1785 & 6.0 \\
\hline Theology & 610 & 85 & 410 & 85 & 53 & 1 & 4 & 1248 & 4.2 \\
\hline Subtotal Humanities & 9005 & 2165 & 2587 & 587 & 308 & 165 & 244 & 15041 & 50.3 \\
\hline Criminology & 741 & 95 & 24 & 1 & 2 & 2 & 1 & 866 & 2.9 \\
\hline Economics \& Business & 1472 & 2379 & 297 & 32 & 52 & 157 & 53 & 4442 & 14.8 \\
\hline Educational sciences & 626 & 530 & 63 & 7 & 8 & 7 & 16 & 1257 & 4.2 \\
\hline Political science & 781 & 217 & 204 & 33 & 21 & 1 & 3 & 1260 & 4.2 \\
\hline Psychology & 617 & 2085 & 84 & 5 & 5 & 18 & 24 & 2838 & 9.5 \\
\hline Sociology & 1211 & 1701 & 123 & 10 & 7 & 8 & 10 & 3070 & 10.3 \\
\hline Subtotal Social sciences & 5735 & 7656 & 873 & 99 & 101 & 257 & 119 & 14840 & 49.6 \\
\hline Total unique records & 14146 & 10576 & 3390 & 671 & 404 & 399 & 335 & 29921 & 100.0 \\
\hline$\%$ & 47.3 & 35.3 & 11.3 & 2.2 & 1.4 & 1.3 & 1.1 & 100.0 & \\
\hline
\end{tabular}

When interpreting the data presented above, one must bear in mind that the numbers of $\mathrm{PhD}$ students, postdocs and tenured staff differ substantially from faculty to faculty and that not every discipline is lectured at each of the five Flemish universities. For example, only the universities of Brussels (VUB), Ghent (UGent) and Leuven (K.U.Leuven) have research groups in archaeology, whereas each university has a faculty of law and a faculty of economics \& business. The numbers and percentages listed here therefore only provide information on the weight of a discipline within the total number of peer reviewed Flemish publications in the broad field of the SSH. The data as such do not give any indication as to the productivity of scholars within a given discipline.

Figure 2 depicts the proportions by discipline of the VABB-GP and VABB-WoS publications in the VABB-SHW. The spider chart shows that the share of VABB-GP publications is higher than that of VABB-WoS publications for most disciplines and for all disciplines in the Humanities. Hence the percentage of WoS-indexed publications in the Humanities (15.5\%) is much lower than in the Social sciences $(53.3 \%$ ). Disciplines with over $80 \%$ of VABB-GP publications are Law (96.7\%), Theology (93.1\%), Literature (89.0\%), Criminology (88.8\%), History (85.1\%), and 
Political science (82.7\%). The disciplines Psychology (25.5\%), Economics \& Business (42.9\%), and Sociology (44.3\%), all three belonging to the Social sciences, display a lower percentage of publications in the VABB-GP compared to the VABB-WoS. By and large these percentages of WoS coverage reflect the percentages that have been reported in the literature (Nederhof, 2006; Sivertsen, 2009).

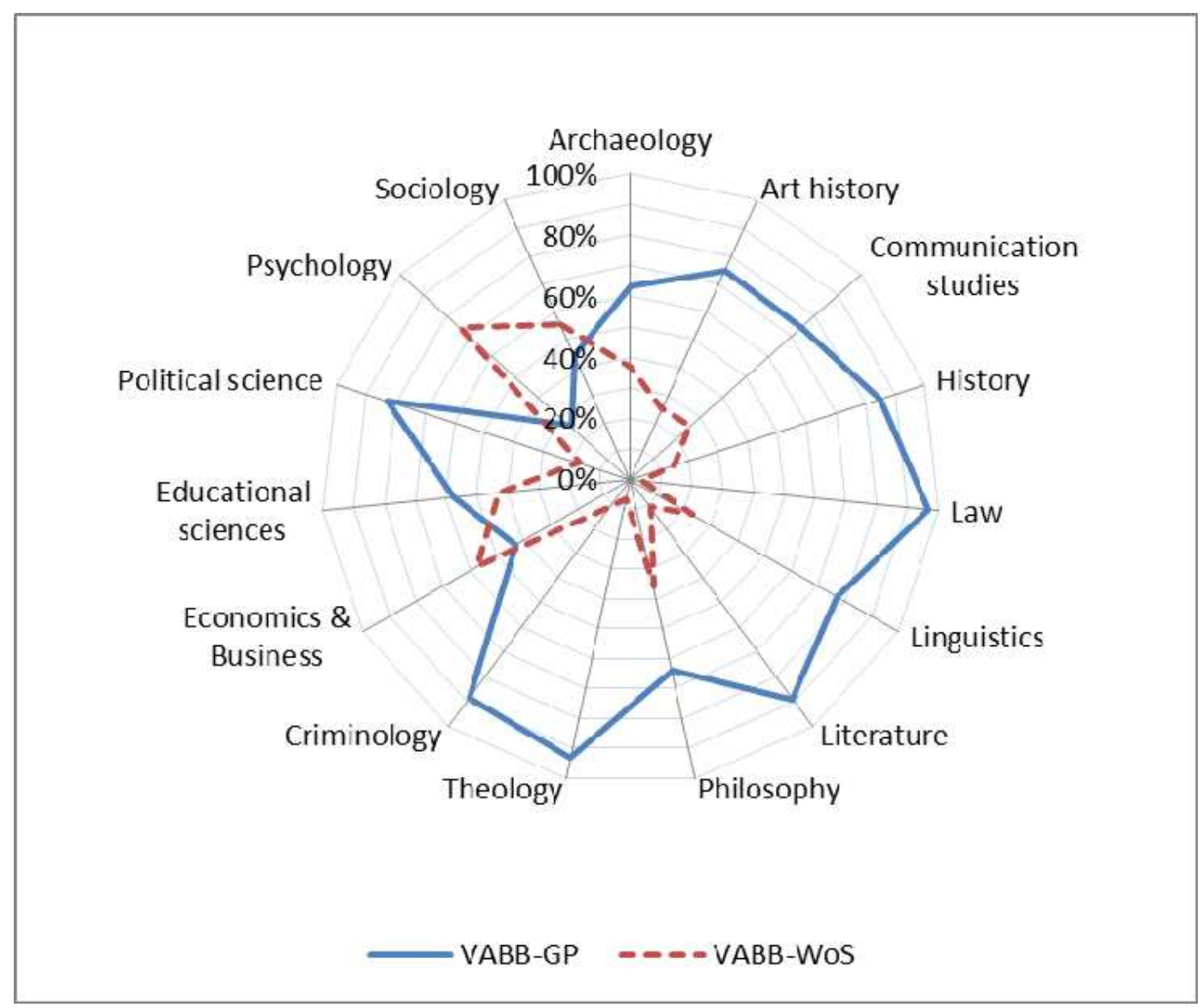

Figure 2: Proportions of VABB-GP and VABB-WoS publications in the VABB-SHW by discipline.

\section{A growth in publications}

It can be deduced from the 2011 BOF-key that the number of SCIE-indexed publications with the author or at least one co-author affiliated with a Flemish university rose from 5515 to 9941 throughout the period 2000-2009, i.e. an 80\% increase. The VABB-SHW now allows to compare this growth with that of the publications by SSH researchers affiliated with a Flemish university. 


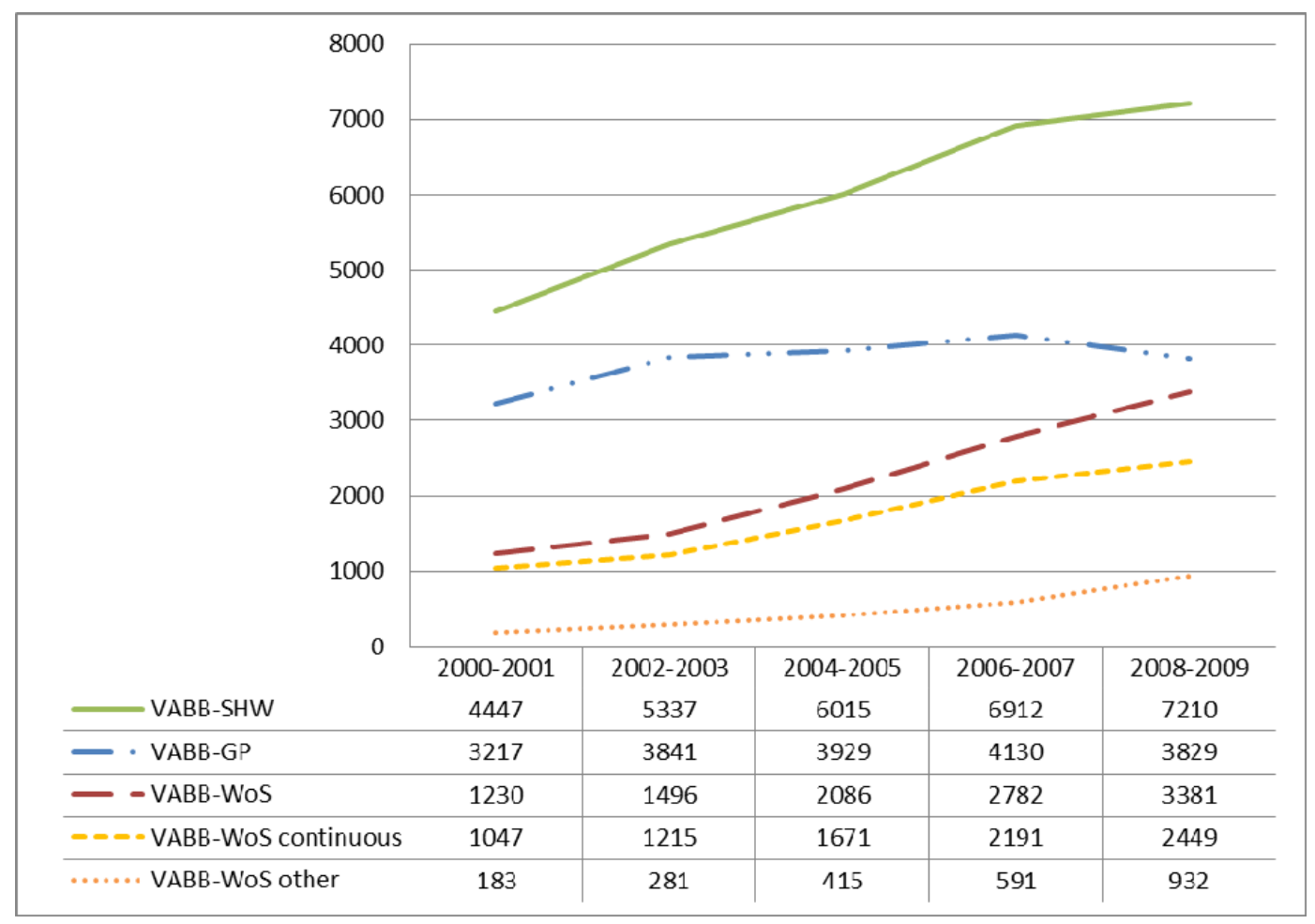

Figure 3: Number of VABB-SHW (VABB-GP and VABB-WoS) publications per two year period. The VABB-WoS publications are further subdivided into articles that appeared in journals that have been indexed in the WoS throughout 2000-2009 (VABB-WoS continuous) and articles that appeared in proceedings or journals that have not been indexed in the WoS throughout 20002009 (VABB-WoS other).

Figure 3 shows the evolution of the number of VABB-SHW publications (including a breakdown into VABB-GP and VABB-WoS publications) between 2000-2009. We observe a $62.1 \%$ increase of the number of publications when comparing 2000-2001 to 2008-2009. This growth in the number of publications/year can mainly be ascribed to the almost tripling (+174.9\%) of the number of publications comprised in the VABB-WoS. Given that for several years only WoS indexed publications contributed to the Flemish performance-based funding model for university research, this result is not too surprising (Ossenblok, Engels, \& Sivertsen, 2012). As shown in Figure 3, two factors are driving this steep increase in WoS coverage. First, researchers have more often targeted WoS covered journals, as is apparent from the $133.9 \%$ increase of the number of articles published in journals that have been covered by the WoS throughout the period 2000-2009 (VABB-WoS continuous). Second, the expansion of the WoS allowed for a very steep 409.3\% increase of the number of articles published in proceedings (from 50 to 74) or journals (from 133 to 858) that have not been indexed in the WoS throughout the period 2000-2009 (VABB-WoS other). Apart from the addition of new journals, the latter observation is mainly due to the fact that a large number of journals have been additionally indexed in the WoS since 2007 (Moed et al., 2009). Given that these journals often have a regional rather than international scope, we should be careful in inferring increased internationalization from the overall increase of the number of WoS publications. Still, considering the fact that the journals that have been indexed in the WoS 
continuously are predominantly international journals, we can conclude from the increasing numbers of articles published in these journals that the trend in publishing behaviour to increasingly address an international audience (Fry et al., 2009) also applies to SSH scholars working in Flanders.

Table 2: Growth rates of the VABB-SHW (VABB-GP and VABB-WoS) per two year period and by discipline as compared to the number of publications per discipline in 2000-2001.

\begin{tabular}{|c|c|c|c|c|c|c|}
\hline Discipline & $\begin{array}{c}\text { 2000-2001 } \\
\text { baseline }\end{array}$ & $2002-2003$ & $2004-2005$ & $2006-2007$ & $2008-2009$ & Slope \\
\hline Archeology & 60 & 1.067 & 1.417 & 1.333 & 1.783 & 0.18 \\
\hline Art history & 85 & 1.612 & 1.588 & 1.988 & 1.812 & 0.20 \\
\hline Communication studies & 84 & 1.369 & 1.750 & 2.095 & 2.452 & 0.36 \\
\hline History & 208 & 0.913 & 1.149 & 1.558 & 1.620 & 0.19 \\
\hline Law & 789 & 1.256 & 1.266 & 1.305 & 1.075 & 0.02 \\
\hline Linguistics & 317 & 1.391 & 1.331 & 1.644 & 1.596 & 0.14 \\
\hline Literature & 180 & 1.456 & 1.583 & 1.533 & 1.672 & 0.14 \\
\hline Philosophy & 295 & 1.149 & 1.207 & 1.383 & 1.312 & 0.09 \\
\hline Theology & 193 & 0.860 & 1.373 & 1.482 & 1.751 & 0.21 \\
\hline Subtotal Humanities & 2415 & 1.216 & 1.267 & 1.409 & 1.337 & 0.09 \\
\hline Criminology & 138 & 0.971 & 1.152 & 1.413 & 1.739 & 0.19 \\
\hline Economics \& Business & 635 & 1.142 & 1.351 & 1.746 & 1.756 & 0.21 \\
\hline Educational sciences & 154 & 1.273 & 1.623 & 1.974 & 2.292 & 0.33 \\
\hline Political science & 129 & 1.845 & 1.946 & 2.248 & 2.729 & 0.39 \\
\hline Psychology & 317 & 1.303 & 1.760 & 2.199 & 2.688 & 0.43 \\
\hline Sociology & 434 & 1.219 & 1.544 & 1.537 & 1.774 & 0.19 \\
\hline Subtotal Social sciences & 2003 & 1.201 & 1.487 & 1.749 & 1.972 & 0.25 \\
\hline Total unique records & 4447 & 1.200 & 1.353 & 1.554 & 1.621 & 0.16 \\
\hline
\end{tabular}

Table 2 lists the VABB-SHW publication counts by discipline for the years 2000-2001, the growth rates as compared to this baseline for 2002-2003, 2004-2005, 2006-2007 and 2008-2009, and, as a measure of average growth, the slope through the growth rates (the growth rate for 2000-2001 being 1). The number of publications has been growing in all disciplines, as is apparent from the positive slope values. However, large variability between disciplines can also be observed: the slopes range from 0.02 to 0.43 and the standard deviation of the 2008-2009 growth factors per discipline is 0.47 . Whereas Law, because of an apparent drop in number of publications in 20082009, grew only $7.5 \%$, Political Science grew 172.9\%. Other disciplines that more than doubled their output are Educational sciences $(+129.2 \%)$, Communication studies $(+145.2 \%)$, and Psychology $(+168.8 \%)$. Overall, growth is stronger in the Social sciences $(+97.2 \%)$ than in the 
Humanities $(+33.7 \%)$, although the latter percentage is tempered by the very modest growth in Law.

Further investigation into the causes underlying the rapid growth in number of publications might disclose whether there are any objective reasons for the considerable differences in growth ratio between the various disciplines. Some disciplines may have experienced an above average growth in staff and researchers, e.g. because of a rapid increase of the number of students. Differences in growth rates may also be explained through swifts in language use and type of publications if, for example, publishing more in English over time leads to more co-publishing with international colleagues. Such multiplicator effects might be important in understanding the difference in growth rate between the Humanities and the Social Sciences, and might contribute to a better understanding of the (lack of) growth in Law. What can already be concluded without further studies is that scholars in the SSH in Flanders annually account for an increasing number of publications, both in total and by discipline. However, especially in the Humanities, growth in some disciplines seems to be stagnating or even reversing the last few years.

\section{Shifts in language use}

In addition to a growth in the number of publications, several studies have also reported shifts in publishing behaviour, in particular an increase in the number of outputs written in English (Kyvik, 2003; Prpic, 2007). This trend is also reflected in the VABB-SHW, in which English as scientific language equally assumes an increasingly important place.

Figure 4 illustrates that the share of publications in English included in the VABB-SHW increased from $61.1 \%$ in $2000-2001$ to $74.6 \%$ in $2008-2009$, whereas conversely the proportion of publications in Dutch dropped from $30.3 \%$ to $19.4 \%$. Likewise, the percentage of publications written in other languages decreased from $8.7 \%$ to $5.9 \%$. 


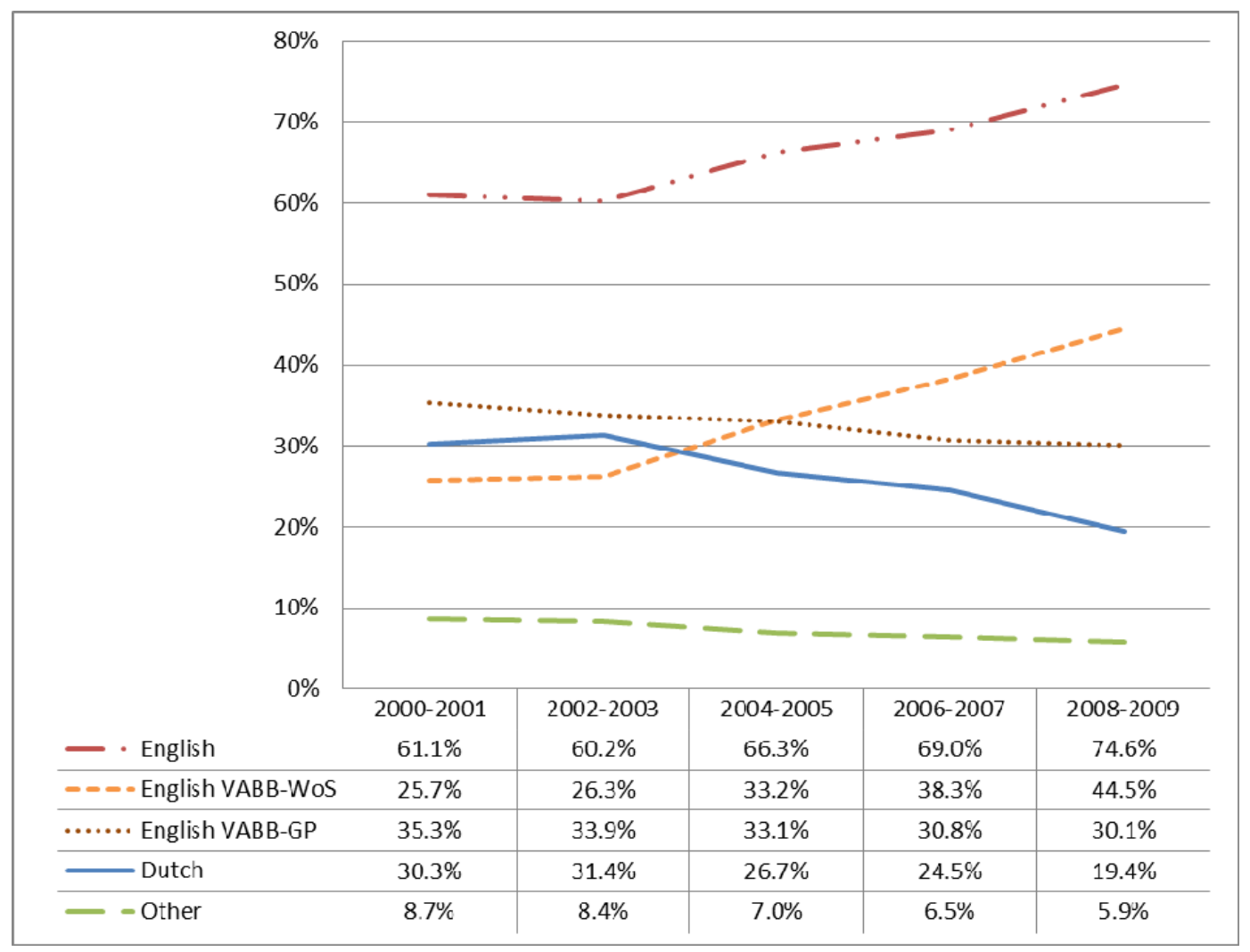

Figure 4: Evolution of the use of English, Dutch and other publication languages within the VABB-SHW (VABB-GP and VABB-WoS).

Figure 4 further shows that the publications written in English are increasingly WoS-indexed. Whereas the share of VABB-GP publications written in English decreased from $35.3 \%$ to $30.1 \%$, that of VABB-WoS publications written in English increased from $25.7 \%$ to $44.5 \%$. The latter evolution is due to the strong rise in VABB-WoS publications (cf. Figure 3), rather than a shift towards WoS-indexed journals publishing in English, because, as Table 3 shows, the vast majority ( $95 \%)$ of VABB-WoS publications for the whole period 2000-2009 are written in English. So although several journals that publish in another language than English are indexed in the WoS, publishing in the WoS remains dominantly in English for SSH researchers working in Flanders. For the VABB-GP too the proportion of publications in English seems to have remained stable, although at a much lower level of about 50\%, except for the last two years during which $56.7 \%$ of the VABB-GP outputs were published in English, as seen in Table 3. 
Table 3: Evolution of the use of English as a publication language within the VABB-GP and the VABB-WoS.

\begin{tabular}{|c|c|c|c|c|c|c|c|c|}
\hline & English in & $\begin{array}{r}2000- \\
2001\end{array}$ & $\begin{array}{r}2002- \\
2003\end{array}$ & $\begin{array}{r}2004- \\
2005\end{array}$ & $\begin{array}{r}2006- \\
2007\end{array}$ & $\begin{array}{r}2008- \\
2009\end{array}$ & Total & Growth \\
\hline \multirow[t]{4}{*}{ Humanities } & VABB-GP & 948 & 1087 & 1190 & 1323 & 1333 & 5881 & 1.406 \\
\hline & & $44.7 \%$ & $41.6 \%$ & $45.7 \%$ & $47.0 \%$ & $52.2 \%$ & $46.3 \%$ & \\
\hline & VABB-WoS & 222 & 247 & 388 & 472 & 566 & 1895 & 2.550 \\
\hline & & $76.0 \%$ & $76.2 \%$ & $85.7 \%$ & $80.6 \%$ & $83.9 \%$ & $81.3 \%$ & \\
\hline \multirow[t]{4}{*}{ Social sciences } & VABB-GP & 657 & 767 & 862 & 877 & 907 & 4070 & 1.381 \\
\hline & & $55.7 \%$ & $56.7 \%$ & $58.6 \%$ & $59.0 \%$ & $63.2 \%$ & $58.8 \%$ & \\
\hline & VABB-WoS & 808 & 1037 & 1483 & 1991 & 2450 & 7769 & 3.032 \\
\hline & & $98.1 \%$ & $98.6 \%$ & $98.4 \%$ & $98.7 \%$ & $97.5 \%$ & $98.2 \%$ & \\
\hline \multirow[t]{4}{*}{ Total } & VABB-GP & 1571 & 1808 & 1989 & 2126 & 2170 & 9664 & 1.381 \\
\hline & & $48.8 \%$ & $47.1 \%$ & $50.6 \%$ & $51.5 \%$ & $56.7 \%$ & $51.0 \%$ & \\
\hline & VABB-WoS & 1144 & 1405 & 1998 & 2646 & 3212 & 10405 & 2.808 \\
\hline & & $93.0 \%$ & $93.9 \%$ & $95.8 \%$ & $95.1 \%$ & $95.0 \%$ & $94.8 \%$ & \\
\hline
\end{tabular}

Table 3 also presents the evolution of the use of English as a publication language for the Humanities and the Social Science separately. For both the VABB-GP and the VABB-SHW the share of publications in English is considerably larger for the Social sciences $(58.8 \%$ and $98.2 \%$, respectively) than for the Humanities (46.3\% and $81.3 \%$ respectively).

Underlying these differences between the Humanities and the Social sciences are differences between disciplines. Figure 5 provides an overview by discipline of the proportion of publications written in English, Dutch and other languages. Clearly, English is dominant in the Social sciences except Criminology, which has $63.2 \%$ publications in Dutch. Only in the discipline of Law there is a still larger share $(64.5 \%)$ of publications in Dutch. All other disciplines have more publications in English than in Dutch. Outstanding disciplines in this respect are Psychology and Economics \& Business with $88.9 \%$ and $88.7 \%$ of publications written in English, respectively.

The importance of publications written in languages other than Dutch or English is particularly apparent in the disciplines Linguistics and Literature with $30.4 \%$ and $21.6 \%$ of the publications belonging to this category. About two thirds of these publications are in French which in Belgium is not only the forum language of romanicists but is also the second language of the country spoken by a large majority in Brussels and Wallonia. The latter fact reflects in the overall dominance of French among the publications in other languages than Dutch or English. $4.7 \%$ of all VABB-SHW publications are in French. These are mainly in the Humanities $(8.1 \%$ of all Humanities publications are in French), but also in the Social sciences (1.4\%, i.e. three quarters of the total of $1.9 \%$ of publications published in other languages than Dutch or English). 


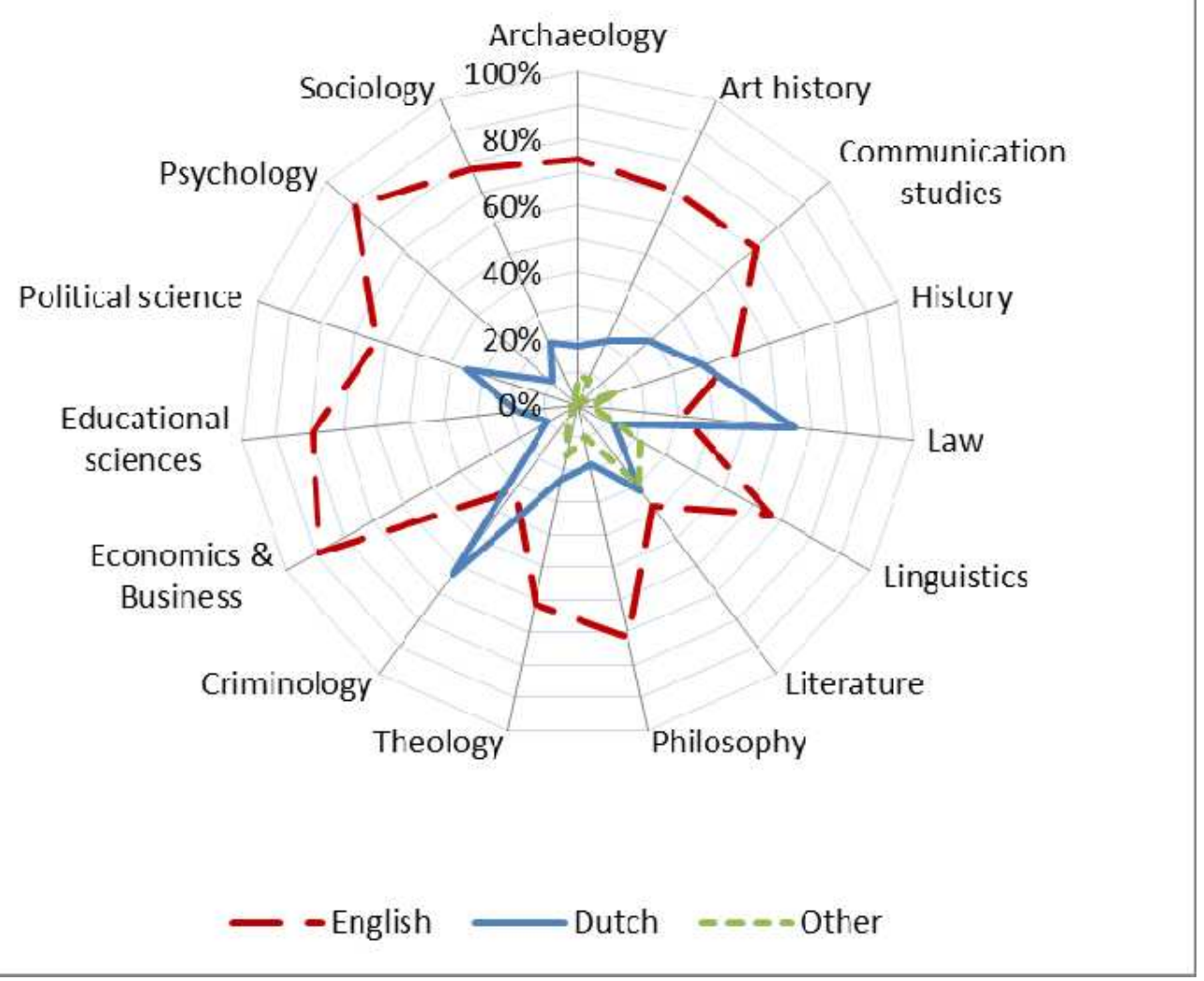

Figure 5: Percentages of publications in English, Dutch and other languages by discipline.

\section{Shifts in publication type}

As already mentioned the VABB-SHW data show that also the SSH scholars in Flanders have focused more on publishing in internationally oriented journals in the past decade. Increasing preference is given to WoS-indexed international journals as outlets for articles. Does this evolution also lead to less book publishing in absolute numbers and/or proportionally? Studies have reported an increased use of the journal article as medium of dissemination, not only in the social sciences (Adams \& Testa, 2011), but also in the humanities (Thompson, 2002). And although the importance of book publishing in the social sciences and humanities has been clearly demonstrated (Nederhof, 2006; Nederhof, Van Leeuwen, \& van Raan, 2010), reports that book publishing is under pressure and the fear that it might in the end even disappear seem to be widespread (Johnston et al., 2009; Williams, Stevenson, Nicholas, Watkinson, \& Rowlands, 2009).

Figure 6, however, shows that the evolution of the publication type shares differs between the Humanities and the Social sciences. Not only, as already observed, is the increase in number of publications steeper in the Social sciences than in the Humanities. Moreover, the proportion of journal articles evolves differently for both. In the Humanities the share of journal articles slightly declined from $77.8 \%$ in $2000-2001$ to $72.7 \%$ in $2008-2009$. In the Social sciences, however, the 
share of journal articles has increased from an already very high level of $90.3 \%$ to $93.3 \%$. Contrary to the evolutions with regard to language use, these evolutions are slow and barely detectable at the level of the individual disciplines. In conclusion, no overall shift towards the journal article as the chosen publication vehicle is observed in the SSH in Flanders in the period 2000-2009. Rather, the publication habits of the Humanities and the Social Sciences seem to be diverging, with only the latter opting for the journal article dominated model (cf. Adams \& Testa, 2011).

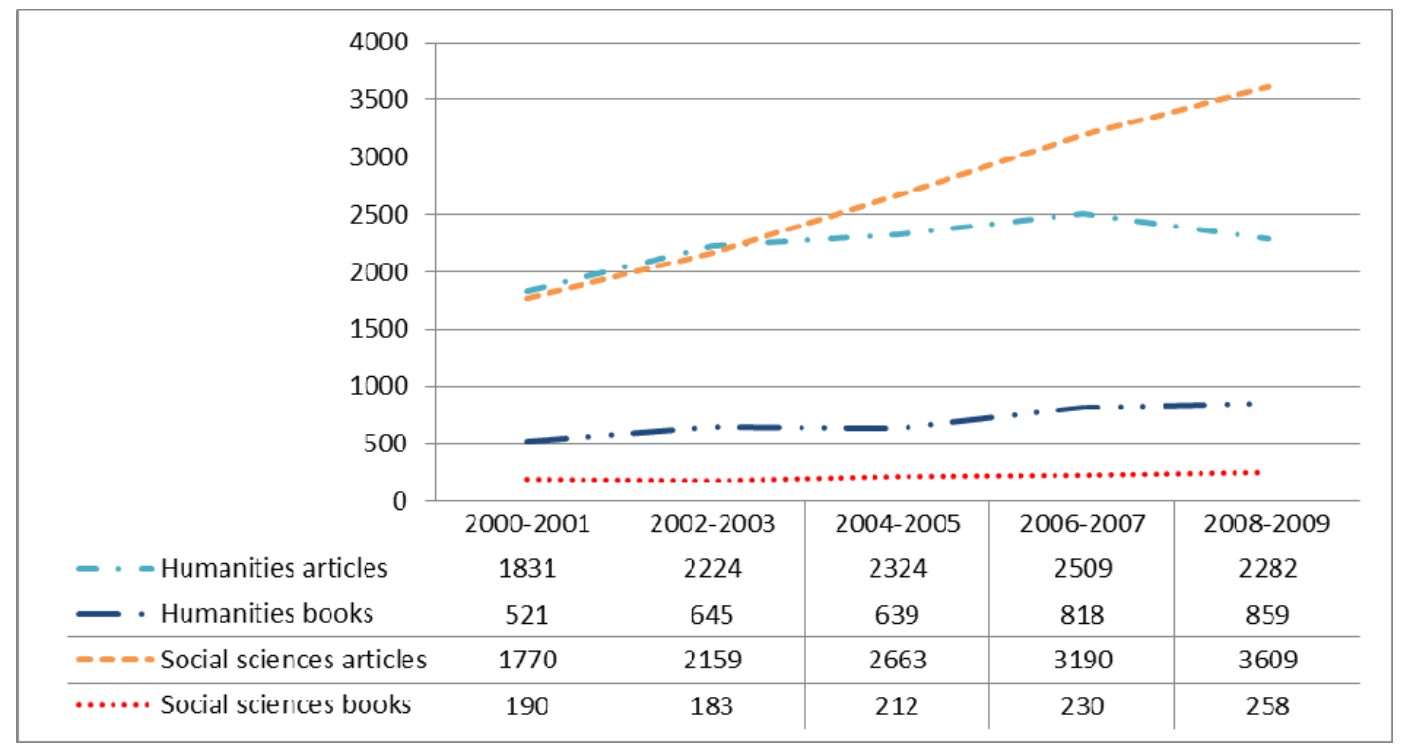

Figure 6: Evolution of the publication type shares in the VABB-SHW (VABB-GP and VABBWoS) for the Humanities and the Social sciences.

The disciplines that are most dominated by journal articles are Criminology, Educational Sciences, Psychology, and Sociology, with each over $90 \%$ of output in the form of journal articles, although the percentage for Sociology would drop below $90 \%$ if social health sciences were separated from mainstream sociology. As shown in Figure 7, Political science is the only discipline of the Social sciences where book publications represent more than $20 \%$ of the output. This appears to be due to the fact that political scientists more frequently than other social scientists in Flanders choose an international book publisher. In the Humanities, however, the dominance of journal articles is less pronounced, with book publications accounting for more than a quarter of the output in Art history, Linguistics, Literature, and Theology. 


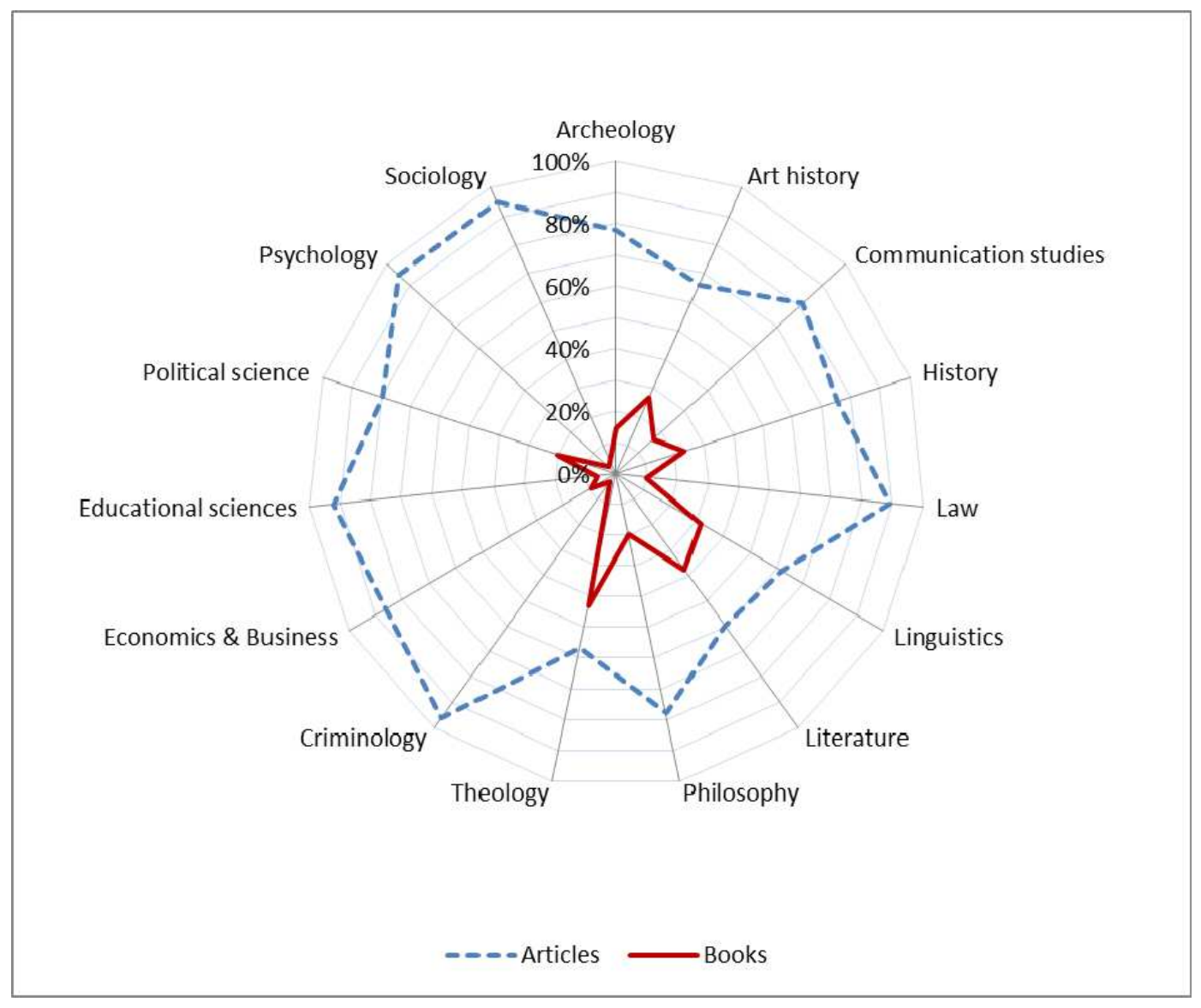

Figure 7: Percentages of publication types (journal articles and books, i.e. books as author, edited books, book chapters) by discipline.

\section{Future perspectives}

The BOF regulation provides an annual update of the VABB-SHW. Each year by April $1^{\text {st }}$ the universities will submit the metadata of their new (and newly registered) publications to the ECOOM, which will allow it to provide the GP with new lists of journals and publishers that SSH researchers working in Flanders have published in or with. This will allow the GP to further refine its judgement, also because the universities can and have asked for the revision of the decision with regard to specific journals. In particular, the GP intends (1) to include more publishers, or at least more book publications, and (2) to implement differential weighting of journals articles and book publications according to prestige of the journals and the publishers in future versions of the VABB-SHW (Ghesquière et al., 2011). By the end of 2012 the decisions of the GP will be evaluated by a committee of international experts, thus providing for an independent expert validation of the application of the BOF criteria to the lists submitted to the GP.

Meanwhile, the further development of the VABB-SHW is not happening in a vacuum. Several professors, including members of the GP, criticised the limited range of book publishers selected for the first version. The main reason is that the selection resulted in the inclusion in the VABBSHW of only $17.0 \%$ of the total of 26222 records with a correct ISBN and consisting of at least 
four pages. Thus, a total of 21757 records $(83.0 \%)$ were not included because the publisher had not been selected for the VABB-SHW. A ranking of these publishers according to frequency reveals that the first 11 publishers are local publishers that together account for almost half $(44.9 \%)$ of the non-approved book publications. Among the 50 most frequently occurring publishers only 7, representing $4.9 \%$ of the non-approved book publications, can be considered international publishers. In view of this data the launch of the Guaranteed Peer Reviewed Content (GPRC) label by the Flemish Association of Publishers ("Vlaams Uitgeversvereniging" or "VUV") is especially promising. Faced with the prospect of most of their publications by academics being excluded from the VABB-SHW because of lack of demonstrable peer review, the publisher association decided to implement the GPRC-label in order to make peer review explicit and traceable (see, for more information, www.boekenvak.be/gprc). This development allows the GP to include books published with local publishers in future versions of the VABB-SHW. In view of the selection of more books published with international book publishers the recent launch of the Thomson Reuters Book Citation Index is a new development that is closely followed. The new index might be used as an aid to identify more peer reviewed books and book series. As a result of these developments future versions of the VABB-SHW might contain a larger proportion of book publications.

In addition, the VABB-SHW remains the subject of and source for scientific research on distinct aspects of the publishing behavior in the SSH in Flanders, as well as on evolutions in this publication behavior. Such analysis yields useful information that permits to place the publishing behavior of Flemish SSH scholars in an international frame. Several foreign studies as well as the present analysis of the first version of the VABB-SHW demonstrate that scholarly communication within the SSH is subject to strong evolution. Will scholars continue to publish at an ever increasing rate? Will the use of English as publication language continue to gain momentum? Will the future indeed see a shift towards journals or books as the medium of dissemination? Finally, further research on the typical publishing behavior of individual disciplines will provide more profound insight into the specific dynamics governing the development of scholarly communication.

\section{Conclusion}

The scientific landscape in Flanders has experienced profound changes in recent years. In 2003 the Flemish government decided to introduce a performance-based funding system for university research in which the number of publications annually generated by scholars at each Flemish university is one of the key indicators. Because of the limited coverage of the Web of Science of publications in the social sciences and humanities, the government decided by the end of 2008 that an additional database covering the publication data of scholars active in Flanders in the SSH, the so-called VABB-SHW, needed to be constructed.

This article presents a first analysis of the VABB-SHW database. The study reveals that the annual number of publications by SSH scholars working in Flanders increased significantly in the past 
decade, with output in the Social sciences growing faster than output in the Humanities. We also observe an outspoken increase in the absolute and relative number of publications written in English, which is mostly due to a rapid increase in the number and percentages of WoS-indexed publications. However, we did not find an overall shift towards publishing journal articles. Rather, publishing journal articles remains dominant in the Social sciences but might be somewhat on the return in the Humanities. In sum, more is being published, more often in English and in WoSindexed journals, but there are no indications that there are proportionally more journal articles and less book publications.

\section{Acknowledgements}

The authors thank all colleagues who helped in building and analyzing the VABB-SHW database, in particular the colleagues in the libraries and the departments of research affairs, the chair and the members of the GP, and Rudi Baccarne, Kirsten Cornelissen, Jan Corthouts, Koenraad Debackere, Nele Dexters, Alain Descamps, Danielle Gilliot, Wolfgang Glänzel, Marc Luwel, Saskia Peersman, Richard Philips, Ronald Rousseau, and Bart Thijs. We are grateful to the Flemish Government for providing an adequate legal framework and funding.

\section{Reference list}

Adams, J. \& Testa, J. (2011). Thomson Reuters Book Citation Index. In E. Noyons, P. Ngulube, \& J. Leta (Eds.), The 13th conference of the International Society for Scientometrics and Informetrics (pp. 13-18). Durban, South Africa: ISSI, Leiden University and University of Zululand.

Archambault, E., Vignola-Gagne, E., Cote, G., Lariviere, V., \& Gingras, Y. (2006). Benchmarking scientific output in the social sciences and humanities: The limits of existing databases. Scientometrics, 68, 329-342.

Debackere, K. \& Glänzel, W. (2004). Using a bibliometric approach to support research policy making: The case of the Flemish BOF-key. Scientometrics, 59, 253-276.

Debackere, K. \& Glänzel, W. (2008). Evidence-based bibliometrics: A decade of bibliometricsbased science policy in Flanders. In J. Gorraiz \& E. Schiebel (Eds.), 10th International Conference on Science and Technology Indicators (pp. 123-125). Vienna, Austria: Austrian Research Centres.

Engels, T. C. E., Spruyt, E. H. J., Glänzel, W., \& Debackere, K. (2009). Het Vlaams Academisch Bibliografisch Bestand voor de Sociale en Humane Wetenschappen: instrument ten dienste van een optimaal wetenschapsbeleid? Tijdschrift voor Onderwijsrecht \& Onderwijsbeleid, 2008-09, 395-403.

Fry, J., Creaser, C., Butters, G., Craven, J., Griffiths, J., \& Hartley, D. (2009). Communicating knowledge: How and why researchers publish and disseminate their findings. Supporting paper 4: Literature review. London: Research information Network. 
Ghesquière, P., Van Bendegem, J.-P., Gillis, S., Willems, D., \& Cornelissen, K. (2011). Het VABB-SHW: eerste versie klaar, nu verfijnen. In K. Debackere \& R. Veugelers (Eds.), Vlaams Indicatorenboek 2011 (pp. 260-264). Brussel: Expertisecentrum O\&O Monitoring.

Hicks, D. (2004). The four literatures of social science. In H. F. Moed, W. Glänzel, \& U. Schmoch (Eds.), Handbook of quantitative Science and Technology Research: The use of publication and patent statistics in studies of S\&T systems (pp. 473-496). Dordrecht: Kluwer Academic.

Hicks, D. (2012). Performance-based university research funding systems. Research Policy, 41, 251-261.

Hornbostel, S. (2008). Gesucht: Aussagekräftige Indikatoren und belastbare Datenkollektionen. Desiderate geisteswissenschaftlicher Evaluierung in Deutschland. In E. Lack \& C. Markschies (Eds.), What the hell is quality? (pp. 55-73). Frankfurt/New York: Campus Verlag.

Johnston, R., Richards, K., Gandy, M., Taylor, Z., Paasi, A., Fox, R. et al. (2009). The future of research monographs: an international set of perspectives. Progress in Human Geography, 33, 101-126.

Kyvik, S. (2003). Changing trends in publishing behaviour among university faculty, 1980-2000. Scientometrics, 58, 35-48.

Luwel, M. (2000). A bibliometric profile of Flemish research in natural, life and technical sciences. Scientometrics, 47, 281-302.

Martin, B., Tang, P., Morgan, M., Glänzel, W., Hornbostel, S., Lauer, G. et al. (2010). Towards a bibliometric database for the social sciences and humanities - A European scoping project: A report produced for DFG, ESRC, AHRC, NWO, ANR and ESF. Sussex: Science and Technology Policy Research Unit.

Moed, H. F., Linmans, A. J. M., Nederhof, A., Zuccala, A., López Illescas, C., \& de Moya Anegón, F. (2009). Options for a comprehensive database of research outputs in social sciences and humanities. Research report to the project board of the scoping study "Towards a bibliometric database for the social sciences and humanities". Leiden \& Madrid: CWTS \& CSIC.

Moed, H. F., Luwel, M., Houben, J. A., Spruyt, E., \& Van Den Berghe, H. (1998). The effects of changes in the funding structure of the Flemish universities on their research capacity, productivity and impact during the 1980's and early 1990's. Scientometrics, 43, 231-255.

Moed, H. F., Luwel, M., \& Nederhof, J. (2002). Towards research performance in the humanities. Library trends, 50, 498-520.

Nederhof, A. J. (2006). Bibliometric monitoring of research performance in the Social Sciences and the Humanities: A review. Scientometrics, 66, 81-100.

Nederhof, A. J., Van Leeuwen, T., \& van Raan, A. (2010). Highly cited non-journal publications in political science, economics and psychology: a first exploration. Scientometrics, 83, 363374.

Ossenblok, T. L. B., Engels, T. C. E., \& Sivertsen, G. (2012). The representation of the social sciences and humanities in the Web of Science. A comparison of publications patterns and incentive structures in Flanders and Norway (2005-2009). Manuscript under review. 
Prpic, K. (2007). Changes of scientific knowledge production and research productivity in a transitional society. Scientometrics, 72, 487-511.

Schneider, P. (2009). An outline of the bibliometric indicator used for performance-based funding of research institutions in Norway. European Political Science, 8, 364-378.

Sivertsen, G. (2009). Publication patterns in all fields. In F. Aström, R. Danell, B. Larsen, \& J. W. Schneider (Eds.), Celebrating scholarly communication studies: A Festschrift for Olle Persson at his 60th birthday (pp. 55-60). ISSI.

Sivertsen, G. (2010). A performance indicator based on complete data for the scientific publication output at research institutions. ISSI Newsletter, 6, 22-28.

Thompson, J. W. (2002). The death of the scholarly monograph in the humanities? Citation patterns in literary scholarship. Libri, 52, 121-136.

Williams, P., Stevenson, I., Nicholas, D., Watkinson, A., \& Rowlands, I. (2009). The role and future of the monograph in arts and humanities research. Aslib Proceedings, 61, 67-82. 